\title{
The New Agenda 2020+5 and the Future Challenges for the Olympic Movement
}

\begin{abstract}
By Mario Nicoliello*
In March 2021, the Session of the International Olympic Committee (IOC) has approved a new strategic roadmap, Olympic Agenda 2020+5, consisting of 15 recommendations. The title, Olympic Agenda 2020+5, has been chosen to reflect the fact that this new roadmap is the successor to Olympic Agenda 2020 and will guide the work of the IOC until 2025. Olympic Agenda 2020+5 builds on the results of Olympic Agenda 2020, which, in the six years since it was adopted in December 2014, has had a profound impact. It has strengthened the IOC by introducing changes intended to make the Olympic Games fit for the future, safeguard the Olympic values, and strengthen the role of sports in society. The 15 recommendations that make up Olympic Agenda 2020+5 are based on key trends concerning areas where sport and the values of Olympism can play a role in turning challenges into opportunities. The recommendations call upon the IOC to: strengthen the uniqueness and the universality of the Olympic Games; foster sustainable Olympic Games; reinforce athletes' rights and responsibilities; continue to attract the best athletes; further strengthen safe sports and the protection of clean athletes; enhance and promote the Road to the Olympic Games; coordinate the harmonisation of the sports calendar; grow digital engagement with people; encourage the development of virtual sports and further engage with video gaming communities; strengthen the role of sport as an important enabler for the UN Sustainable Development Goals; strengthen the support to refugees and populations affected by displacement; reach out beyond the Olympic community; continue to lead by example in corporate citizenship; strengthen the Olympic Movement through good governance; innovate revenue generation models. The paper aims at analysing how principles contained in the Agenda 2020+5 can redesign a more inclusive model of the Olympic Games, with respect to all the stakeholders.
\end{abstract}

Keywords: Agenda 2020+5, Olympic movement, IOC; Olympic Games

\section{Introduction}

Thomas Bach would have liked to be re-elected in Athens, and the next day to go to the Sanctuary of Olympia, where everything began 776 years before the birth of Christ. However, COVID-19 got in the way, so his plans were impacted. The second term of Thomas Bach as President of the International Olympic Committee was therefore officially born online, with the voting carried out from home by members of the Olympic family and the 67-year-old German

\footnotetext{
*Researcher, University of Genoa, Italy.
} 
president who welcomed the result in the Lausanne headquarters, in a dark suit, white shirt and red tie.

Eight years ago, when he took over from Jacques Rogge in the Hilton hotel in Buenos Aires, Thomas Bach was already dreaming of a new four-year mandate to bring his years of reign up to twelve. Two weeks after his election during his first public outing as president, he was in Olympia on the occasion of the lighting of the flame in Sochi. With typical Teutonic air, he told the reporters, "We are waiting for the reforms needed to modernize the Games." No sooner said than done. Just 15 months later, inside the Fairmont in Monte Carlo, Bach launched the 2020 Olympic Agenda - his indelible mark in the history of the Olympic family - the first phase of the reform program, the one linked to the inaugural mandate. Like all far-sighted executives, the number of the IOC also kept the trump card, to bring it down at the beginning of the second term. Therefore, in March 2021 the virtual session released the $2020+5$ Olympic Agenda, the roadmap for the next four years.

The $2020+5$ Agenda is based on the results of the previous 2020 Agenda and consists of 15 recommendations. However, before turning our gaze to the future, it is necessary to focus on the present, because the Tokyo 2021 Olympic Games will not only be the only ones to take place in an odd year, but also the first without a foreign audience in the stands.

The COVID-19 pandemic is undoubtedly the most brutal of the challenges that Thomas Bach had to face as president of the Olympic family. In the face of it, the issue of Russian doping, the absence of candidates for the Games, the protests of the athletes during the competitions all seem insignificant. Yet, on closer inspection, Bach has been able to look beyond the conjuncture in every area, designing a path of structural change. In Russia he stated, "pay the nation, not the clean athlete." In the host cities he extracted the double assignment Paris 2024-Los Angeles 2028 from the hat, and with the Milan-Cortina 2026 combination he enlarged the geography of the Olympic venues.

Starting with the revolutionary assignment of the Games, they will no longer be decided solely by the hands of the Session, but rather will be decided at the table by a Commission that will make the choice after a long dialogue with potential candidates. There will be no more winners and losers, but only cities chosen after a common improvement path of the initial project. To promote sustainable Olympic Games, it will be necessary to limit carbon dioxide emissions, while strengthening the quality of the competitions. It will be necessary to attract the best athletes by harmonizing international calendars (so as not to oversee other events at the same time as the Games), to protect clean sportsmen by severely punishing those who break the rules, protect athletes who are refugees, displaced and involved in war conflicts. On the road to increasing digital involvement, virtual sports and video game communities will also have citizenship rights. Finally, to increase revenue, it will be necessary to go beyond generalist TVs and take advantage of new technologies to expand the audience. The reconfirmed president summed up this up by stating, "When we adopted the 2020 Agenda in 2014, we did so under the motto, still valid today, change or you will be changed. The world around us has continued to evolve. However, difficult the circumstances may appear at the moment, if we draw the right conclusions, we can turn them into opportunities." 
His namesake, Johan Sebastian, played the organ and composed indelible works. He, Thomas from Würzburg, used to stick with foil as a young man, and today builds bridges to ferry Olympism into in the post-coronavirus world.

While introducing the debates during the Virtual IOC Session in March 2021, Thomas Bach explained: "The coronavirus crisis has changed our world in fundamental ways. The world will never again be like it was before. Even once we have finally overcome the health crisis, we will face the far-reaching social, financial, economic and political consequences." He continued: "As leaders of the Olympic Movement, we must prepare ourselves for this new world. In order to shape our future, we need a vision of how this new world will look like." According to the IOC (2021), the 15 recommendations that make up Olympic Agenda 2020+5 have been developed through an inclusive and collaborative process. They are based on key trends that have been identified through robust research, as likely to be decisive in the post-coronavirus world. There are also areas where sport and the values of Olympism can play a key role in turning challenges into opportunities. Following the IOC discussion, the five trends that have been identified are: solidarity; digitalisation; sustainability; credibility; and cconomic and financial resilience.

Concluding his introduction during the Virtual Session, President Bach commented: "Olympic Agenda 2020+5 as our vision for the future of the Olympic Movement addresses these overarching trends. The aim is to build even more solidarity, to harness the positive potential of digitalisation, to be the impactful enabler to achieve the UN Sustainable Development Goals, to strengthen the credibility of the constituents of the Olympic Movement, and to join forces with other values- or purpose-driven organisations."

He thanked everyone who had participated, saying: "The 15 recommendations have been developed in a collaborative initiative, involving all stakeholders of the Olympic Movement, but especially with input and feedback from all the IOC Members, in particular through work and contribution in the different IOC Commissions. Olympic Agenda 2020+5 has been developed by all of us and therefore belongs to the entire Olympic Movement."

This paper aims to analyse the recommendations contained in the $2020+5$ Olympic Agenda and how these indications could redesign a more inclusive model of the Olympic Games with respect to all the stakeholders.

After this introduction, the paper continues with the methodology part, then in the conceptual framework, the Olympic Agenda 2020 will be matched with the previous literature and with the analysis of the stakeholders of the Olympic Games. The results contain the analysis of Olympic Agenda 2020+5, while the discussion is the section containing the original contribution, obtained by putting together the Agenda 2020, the Agenda 2020+5 and the stakeholders of the games. Finally, the conclusion summaries the results and indicates the future developments. 


\section{Methodology}

The objective of the work is to carry out a qualitative analysis to bring together the theory of stakeholders with the 2020+5 Olympic Agenda. In particular, in the first part of the work, the Olympic Agenda 2020 and the stakeholders of the Olympic Games will be identified. Subsequently, the elements of the 2020+5 Olympic Agenda will be presented as results of this analysis. Finally, the two areas will be put together and it will be outlined how it was possible to define a new business model that is more inclusive of the Olympic Games, starting from the 2020+5 Olympic Agenda and considering the individual stakeholders.

Regarding the collection of data, the basis was the website of the International Olympic Committee (www.olympic org), on which the documents related to the progress of the implementation of the 2020+5 Olympic Agenda were collected.

In particular, the main document was the one released in April 2021 on the occasion of the IOC Session.

\section{Conceptual Background}

Olympic Agenda 2020

Olympic Agenda 2020 is the strategic roadmap for the future of the Olympic Movement. The 40 recommendations are like pieces of a jigsaw puzzle that, when you put together, form a picture that shows the IOC safeguarding the uniqueness of the Olympic Games and strengthening sport in society.

Some of the key areas addressed by Olympic Agenda 2020 are (IOC 2014):

- Changes to the candidature procedure, with a new philosophy to invite potential candidate cities to present a project that fits their sporting, economic, social and environmental long-term planning needs.

- Reducing costs for bidding, by decreasing the number of presentations that are allowed and providing a significant financial contribution from the IOC.

- Moving from a sport-based to an event-based programme.

- Strengthen the $6^{\text {th }}$ Fundamental Principle of Olympism by including nondiscrimination of sexual orientation in the Olympic Charter.

- Launch of an Olympic Channel to provide a platform for sports and athletes beyond the Olympic Games period, 365 days a year.

- Adapting and further strengthening the principles of good governance and ethics to changing demands.

- Athletes remain at the centre of all 40 of the proposals, with the protection of the clean athletes being at the heart of the IOC's philosophy.

This Olympic Agenda 2020 was unanimously agreed upon at the $127^{\text {th }}$ IOC Session in Monaco on the $8^{\text {th }}$ and $9^{\text {th }}$ of December 2014. The reforms follow a year of discussion and consultation with all stakeholders of the Olympic Movement, as well as external experts and the public. More than 40,000 submissions were 
received from the public during the process, generating some 1,200 ideas. Fourteen working groups synthesised the discussions and debates throughout the whole Olympic Movement and wider society before the recommendations were finalised by the Executive Board ahead of the $127^{\text {th }}$ session.

Olympic Agenda 2020 is a set of 40 detailed recommendations whose overarching goal was to safeguard the Olympic values and strengthen the role of sport in society. Identified and collated through a collaborative and consultative process involving Olympic Movement stakeholders and outside experts, they were driven by a recognition that the world was evolving rapidly and that the Olympic Movement had the opportunity to be an agent of change. The motto underpinning the process from identification to adoption to implementation was, "change or be change" - a philosophy that remains as compelling today as it was six years ago (IOC 2015).

Built on the three pillars of credibility, sustainability and youth, the 40 separate yet interrelated recommendations can be likened to a jigsaw puzzle. When all 40 pieces are put together, a picture emerges in which progress in ensuring the success of the Olympic Games, strengthening the role of sport in society, and greater connection with young people and those outside the Olympic Movement becomes apparent. This picture, the outcome of six years of commitment and engagement by all stakeholders, has developed gradually, with the full impacts emerging only now.

"Olympic Agenda 2020 has changed the Olympic Games, the IOC and the Olympic Movement. Having achieved 85 percent of the recommendations is a great example of what we can accomplish when we work together. But it is our conviction that the success of today only gives us the opportunity to drive the change for tomorrow," IOC President Thomas Bach said in December 2020, during the Olympic Forum. He continued: "Carrying forth the unity which Olympic Agenda 2020 created within the Olympic Movement and building on its success, we can contribute to shaping the post-coronavirus world. From this position of strength and stability, we have every reason to be confident about our future, as we continue to pursue our mission to make the world a better place through sport" (IOC 2020).

\section{Literature Review}

The theme of the 2020 Olympic Agenda has been at the center of several analyses conducted by the authors in the past.

In particular, MacAloon (2016) examines the current Olympic bidding crisis and evaluates the accompanying Agenda 2020 reform process at the International Olympic Committee. The organization's decline in public opinion, particularly in Europe, is associated with its recent failure to consistently and convincingly represent the Olympic Movement (as opposed to the Olympic Sport Industry). Using IOC relations with international human rights organizations as a template, real progress in the course of the Agenda 2020 process was achieved, but then suspended or reversed by the selection of Beijing as host of the 2022 Winter Olympic Games. 
Schnitzer and Haizinger (2019) reveal that the 2026 Winter Olympic Games (WOG) hosts plan to reduce the budgets for the organization and the infrastructure costs in the host regions. As a consequence, the number and nature of the sites and venues as well as the distances between them will increase. This means that the future Olympic Heritage $(\mathrm{OH})$ may lay less in iconic buildings, but rather will focus on the attempt to fulfil the city's long-term strategies.

Thorpe and Wheaton (2019) examine the power and politics involved in the process of including three new action sports-surfing, skateboarding and sport climbing-into the Tokyo 2020 Olympic Games. Drawing upon interviews with 20 key individuals involved in the process (e.g., action sport IF Presidents and staff; presidents of action sport national federations; industry members; athletes), and formal and informal communications with IOC staff, they reveal the complex power relationships between the IOC and international action sport governing bodies, and within the International Federations of surfing, skateboarding and sport climbing. Furthermore, they contextualize the inclusion of these new action sports into the Tokyo 2020 programme within Agenda 2020 and significant IOC policy reform. Bringing together a critical sociological engagement of the Olympic Games with a typology of international organizational change, they consider whether Agenda 2020 is a policy signaling deep organizational learning and significant cultural change, or rather a superficial attempt at performing the changes necessary to maintain their dominance in the global sports economy. Despite promises and proclamations of organizational change, they conclude that the inclusion of action sports into the Tokyo 2020 Games is a salient example of the complex operations of hegemony in the highly competitive sports market, with the power of the IOC adapting and enrolling unlikely others into its operations.

According to Mataruna Dos Santos et al. (2019), the Olympic Games is passing through a new phase on the planet. The sport has reformed around the world especially in the Arabic-speaking Gulf countries. The local culture, religion and natural environment are the driving forces that are shaping the behavior of the society. Nowadays, the consumption and sharing of sports information is through the medium of the latest technology, like the tools of social media. The youth belonging to the Gulf Cooperation Council (GCC) countries use sports as a medium to communicate via social media. Their analysis used the situational analysis to describe the challenges of six communication channels for promoting the International Olympic Committee (IOC) Agenda 2020 for the GCC countries based on the SWOT, PESTLE and CATWOE methodologies. The results showed that the geographical area has huge potential to promote high performance and values of sport for future generations of athletes using the Youth Olympic Games as a seasonal door. However, an improvement from the perspective of consumer behavior is necessary to generate youth engagement through National Olympic Committees (NOCs) during Summer and Winter Olympic Games, with a heavy focus on the challenges for the new generation through social media. The recommendation points were that bilingual youth athletes (speaking Arabic and English) should be the new voice of the Olympic Movement in the GCC countries. 
Compared to previous works, this paper intends to investigate how the Olympic Agenda 2020+5 can contribute to designing more inclusive Olympic Games, considering the needs of individual stakeholders.

\section{The Stakeholders of the Olympic Games}

The Olympic Games are configured as a mix of products and services that must be well-coordinated to achieve the set objectives. To ensure an effective combination of these tangible and intangible factors, the contribution of multiple operators, both public and private, is almost always necessary, so as to constitute a project network, given the temporally limited nature of the event, which must be well-selected and organized. It follows the importance of a careful identification of the necessary contributions and, therefore, of the design of the network as well as a subsequent ability to coordinate, formally and informally, the team that has been formed.

The task that should concern the event manager is precisely that of ensuring that the event system is able to interact in a functional way with the elements of the external environment, while ensuring the pursuit of those purposes and objectives deemed to be priority, and guaranteeing finally, a respect for the social climate and the community in which the event is organized and inserted.

Today the Olympic Games must be considered as an economic and social system, in which a multiplicity of players take part, and one in which an equally large number of interlocutors are interested. It is on this principle that the stakeholder theory is based, according to which the social dimension of the company or organizing body joins the more properly entrepreneurial one, and consequently it is appropriate that the effects of the event guarantee a fair balance between the objectives. This is strictly economic, and includes the other repercussions including those of a social nature.

By accepting this vision of the event as a social system with multiple purposes, it follows a series of indications that are connected to each other: in addition to the traditional bearers of capital shares, there may be other categories (the stakeholders) that can also affect the management of the event favoring the creation of positive or negative situations to the activity of the event itself. Stakeholders are interested not only in economic results, but also in the social value that the organization or the events it organizes are able to generate.

The stakeholders of an event are those groups or people who can influence or be influenced by the existence of an event (Freeman and Reed 1983, Clarkson 1995). In particular, the primary stakeholders are those individuals or groups without whose support the event would cease to exist, while the secondary ones are those actors which, although not directly involved in the event, can seriously influence or even prevent the success of the event (Freeman 1984 and 1994).

Taking the view of who has to organize the Olympic Games, the primary stakeholders are: 
- Athletes: people who have an active role in the event, producing the most important part of the Games from the sport side. They participate in the Games with the aim of winning medals and prizes.

- Organizing Committee: They create the Games, setting up the conditions for athletes to compete. The organizers bear the expenses and collect the revenues from local sponsors and spectators.

- International Olympic Committee (IOC): is the body that supervises the Games, choosing the host city and managing TV rights and global sponsorships.

- National Olympic Committees: These are the national bodies that guarantee the participation of athletes in the Games, supporting travel and preparation expenses.

- International Sports Federations: They are the bodies that manage the sports included in the Olympic program. Thanks to the revenues obtained from the IOC they manage to survive.

- Employees: the human resources who are involved in various capacities in the entire event management process, from the realization of the idea to the operational development of the event. Generally, their activity is remunerated.

- Volunteers: they do not receive any monetary compensation, but they can equally play an important role in the process of carrying out the event;

- Sponsor: organizations which collaborate in various capacities in the organization of the event, providing material, intangible and economic resources for carrying out the event itself;

- Suppliers: they provide resources of a different nature in return for a payment;

- Media: they have the potential to promote the knowledge and image of the Games towards the general public.

The secondary stakeholders include:

- Spectators: they sometimes play an active role becoming protagonists through their participation in the event. They buy tickets, contributing to the turnover of the event, and add a touch of color that increases the media value of the Games.

- Local institutions: they may affect the performance of the event by defining the policies and procedures to be respected.

- Host community: it is included among the stakeholders as a result of the fact that generally the events are held in a limited geographical area where citizens and businesses live and work.

- Economic and productive system of the host territory: it includes all those companies that offer various types of services to participants and visitors, also in terms of marketing and sponsorship. 


\section{Results}

\section{The Olympic Agenda 2020+5}

In March 2021, the Session of the International Olympic Committee (IOC) has approved a new strategic roadmap, Olympic Agenda 2020+5, consisting of 15 recommendations, that are based on key trends concerning areas where sport and the values of Olympism can play a role in turning challenges into opportunities. In this paper we analyze the 15 recommendations, highlighting what the objectives of each recommendation are and what the IOC should do to achieve them. The recommendations are analyzed one by one below (IOC 2021).

\section{Strengthen the Uniqueness and the Universality of the Olympic Games}

This principle concerns the preservation and promotion of the universality of the Olympic Games. For example, to preserve the principle of universality through guaranteed continental representation within the Olympic qualification systems; to continue to strengthen the Olympic scholarships for athletes' programme, in particular for those National Olympic Committees (NOCs) in the greatest need; to identify innovations in sport to reflect, as appropriate, in the programme and delivery of the Olympic Games; to consider the addition of physical virtual sports in the Olympic Programme in cooperation with the respective International Federations (IFs).

Secondly, the aim is to make the Olympic Games experience more inclusive by engaging with the largest possible audience. For example, to study the possibility to take some sports events or some parts of the ceremonies out of the stadiums and bringing them to urban and popular settings, or to develop 'phygital' experiences with both physical and digital components, such as for example an online platform during the Olympic Games for fans and stakeholders (e.g., chat with athletes, behind the scenes tour).

Thirdly, the idea is to collaborate with key players in the worlds of sport, entertainment, music and art to enhance all components of the Olympic Games experience (e.g., live sites, open warm-up, virtual sport), and to broadcast the Olympic Games using innovation and athlete-centric storytelling to highlight the relevance of the Olympic values.

\section{Foster Sustainable Olympic Games}

This principle pursues to achieve climate-positive Olympic Games at the latest by 2030, and to support Organising Committees of the Olympic Games (OCOGs) and their partners in developing and monitoring oversight of Olympic Games supply chains and construction workers' rights as part of their human rights approach.

The aim is to ensure that key legacies are achieved before the Olympic Games. The legacy plans a governance structure and long-term funding which are in place early in the lifecycle and encourage IFs and National Federations (NFs) to use facilities of Olympic Hosts. 
The key point is to optimize the delivery of the Olympic Games in partnership with Olympic Movement constituents. To this end, the milestone could be refined allocation of responsibilities between stakeholders (e.g., OCOGs, IFs, NOCs, The Olympic Partners [TOPs], Rights-Holding Broadcasters [RHBs], International Paralympic Committee [IPC], IOC), and to identify cost saving opportunities that evolve the event-based programme with a key focus on simplifying the venue master plan and reducing cost and complexity in each sport. By providing rightsize service levels and avoiding any over-scoping through efficient data capture and sharing programmes, working with stakeholders to streamline numbers of onsite participants, and actively promote opportunities to perform Olympic Gamesrelated tasks remotely the Olympic Games will be able to operate more optimally.

\section{Reinforce Athletes' Rights and Responsibilities}

This principle aims to increase employment opportunities for Olympians and elite athletes within the IOC, to encourage all stakeholders to provide transparency on their support to athletes, to promote and support athletes' rights across the Olympic Movement, to develop guidelines and best practices to support the delivery of the Athletes' Rights and Responsibilities Declaration for athletes and stakeholders, to increase the recognition of Olympians and of the Olympians community (e.g., to develop assets that Olympians can use to promote their status as Olympians, to empower Olympians in acquiring knowledge and developing skills in digital media through Olympic Games-time and online workshops.

\section{Continue to Attract Best Athletes}

This principle widens the scope of engagement with best athletes. Therefore, the purposes concern: to engage with best athletes, in collaboration with IFs, professional leagues, NOCs and player representatives, in order to ensure the motivation of current and emerging generations of best athletes to compete at the Olympic Games; to engage with IFs, NOCs, professional leagues and other sports event organizers; to celebrate the athletes being part of the global Olympians community including through promotion on Olympic broadcasts and digital platforms.

\section{Further Strengthen Safe Sport and the Protection of Clean Athletes}

This principle aims to expand current efforts to protect clean athletes. In the Antidoping field, there is a need to continue to support World Anti-Doping Agency (WADA) and International Testing Agency (ITA) development and implementation of anti-doping programmes, including professional leagues and college sport.

Concerning the prevention of competition manipulation, it becomes necessary to increase awareness and education on integrity, ethical principles and prevention of manipulation of competitions for athletes, their entourage and all officials, including judges and referees, and to encourage IFs to assess and enhance their refereeing and judging systems. 


\section{Enhance and Promote the Road to the Olympic Games}

This principle aims to elevate the profile of thousands of qualifying events by authorizing the use of Olympic branding (e.g., OCOG marks) in a flexible manner and to support the tens of thousands of athletes to narrate their participation in the qualifying events and digitally promote their journey to the Olympic Games. In order to do so, there is a need to amplify engagement with all other stakeholders (e.g., event organizers, local authorities, participating NOCs) involved in the qualification process by offering them opportunities to communicate on this Olympic journey.

\section{Coordinate the Harmonization of the Sports Calendar}

This principle aims to address the number, frequency and scope of multi-sport events to fit with the post-COVID-19 world. To this end, from one side it seems indispensable to coordinate the harmonization of multi-sports event planning across the Olympic Movement to ensure sustainability for all stakeholders; from the other side, it is necessary to ensure that athletes' voice and perspective are part of the decision-making process linked to the planning of sports calendars.

\section{Grow Digital Engagement with People}

This principle aims to use Olympic digital and social media channels to deliver engagement opportunities during and between the Olympic Games. In order to do so, it needs to: build a single, people-centric, digital platform, Olympics.com (e.g., merging the websites and apps of Olympic Games into the single Olympic platform; building a dedicated digital presence, ioc.org, for the IOC as an institution featuring its work and programmes to deliver on its mission); deliver digital content and communications to people for the benefit of the IOC, IFs, NOCs, athletes and OCOGs based on data insights; and use Olympic Channel Services as a hub for content, technology, digital product and data analysis activities in support of the IOC Digital Strategy and the entire Olympic Movement.

\section{Encourage the Development of Virtual Sports and Further Engage with Video} Gaming Communities

This principle aims to leverage the growing popularity of virtual sport to promote the Olympic Movement, Olympic values, sports participation and grow direct relations with the youth. To this end, it is essential to: strengthen the roles and responsibilities of IFs in establishing virtual and simulated forms of sports as a discipline within their regulations and strategies; to launch unique Olympic products and experiences through virtual and simulated forms of sports, in support of the IOC's digital engagement strategy; consider the addition of physical and virtual sports in the Olympic Programme in cooperation with the respective IFs; and make available Olympic athlete-related online programmes and digital tools to the competitive video gaming community to support their physical and mental well-being. 
10. Strengthen the Role of Sport as an Important Enabler for the UN Sustainable Development Goals

This principle aims to build on the existing relationship with UN agencies to influence global social policy change and resource allocation. In order to do so there is a need: to strengthen the cooperation with UN agencies (e.g., WHO, UNESCO, UNHCR, UN Women) to provide opportunities for people who do not usually have access to sport in low and middle-income countries; to create partnerships with Development Banks or other development organizations to increase investment in sport infrastructure and scale the impact of sport for sustainable development; to enable NOCs to promote the Olympic Values at a national level by enhancing Olympic Solidarity's programmes around social development; to enhance cooperation with the IPC on social development programmes.

11. Strengthen the Support to Refugees and Populations Affected by Displacement This principle aims to raise awareness of the global refugee crisis and increase access to sport for people affected by displacement. In next years, IOC will support the Olympic Refuge Foundation to ensure one million forcibly displaced young people have access to safe sport by 2024. At the same time, it would be necessary to provide ongoing support to refugee athletes of all abilities through Olympic Solidarity scholarships and to facilitate refugee athlete participation and access to international- and national-level competitions. The final aim is to measure the impact of the Sport Coalition for Refugees that pledged to improve access for refugees to facilities, sport activity and participation in sporting events and competition

\section{Reach out beyond the Olympic Community}

In order to reach out beyond the Olympic community, IOC needs to engage and interact with diverse social groups focusing on different demographics, geographies and interests (e.g., cultural communities, scientific communities, value-based communities). Then, IOC should reach out to new communities, leveraging strategic and commercial partnerships, fostering dialogue through culture and education, leveraging programmes that reach beyond the Olympic community (e.g., visual, performing, literary artists, architects, designers, educators).

\section{Continue to Lead by Example in Corporate Citizenship}

The aims of IOC regarding this principle are: to be a leader in sustainability; to inspire and assist the Olympic Movement in developing sustainable sports worldwide; to foster gender equality and inclusion; to strengthen the human rights approach.

Regarding sustainability, IOC have to reduce $\mathrm{CO} 2$ emissions in line with the Paris Agreement by $30 \%$ by 2024 and become a "climate positive" organisation through the creation of the "Olympic Forest" and other mitigation measures; to develop a comprehensive education programme across all levels of responsibility, 
and to increase staff competency in implementing the Sustainability Strategy within their areas of responsibility.

Concerning the inspiration, IOC needs to support IFs and NOCs in their transition towards carbon neutrality through the Sport for Climate Action Framework and other means to assist the IFs and NOCs in developing their own sustainability strategies including sourcing and resource management, and to facilitate best practice sharing in sustainable innovation in sport infrastructure.

Regarding inclusion, the IOC should become an example by continuing to increase gender balance at IOC Governance level and adopting a Diversity and Inclusion action plan for its administration. Finally, concerning human rights, IOC could amend the Olympic Charter and the "Basic Universal Principles of Good Governance" of the Olympic and Sports Movement to better articulate human rights responsibilities.

\section{Strengthen the Olympic Movement through Good Governance}

The route in front of the IOC about this principle is full of new challenges. In particular, IOC should update the "Basic Universal Principles of Good Governance" to the latest standards, to foster the compliance of all the Olympic and recognize IFs, NOCs, IOC-Recognized Organizations with the "Basic Universal Principles of Good Governance," to initiate the self-assessment of the Recognized Federations and Organizations concerning compliance with the "Basic Universal Principles of Good Governance," to strengthen the involvement of Olympic Movement stakeholders in the International Partnership Against Corruption in Sport (IPACS) to increase the effectiveness of anti-corruption measures.

\section{Innovate Revenue Generation Models}

The last principle regards the economics of Olympic Games. The aim of IOC is to innovate revenue generation models to ensure long-term viability of the Olympic Movement. In order to do so, it needs to consider alternative transmission methods, such as free digital, to complement traditional free-to-air television; to ensure official Olympic broadcasters, sponsors and other commercial partners and programmes support and benefit from the IOC Digital Strategy, to evolve and enhance the TOP Sponsorship Programme, to create a centralized Olympic hospitality programme for the benefit of all Olympic stakeholders and finally to diversify Olympic revenue sources (such as global e-commerce, commercialization of social media and Olympic-related gaming).

\section{Discussion}

The recommendations contained in the 15 points of the $2020+5$ Olympic Agenda can be declined, considering first of all their time horizon and the link with stakeholders (Table 1). In regards to the time horizon, the recommendations are divided into short-term (within the year, therefore within 2022) or mediumterm (within 4 years, therefore within 2025). The stakeholders, on the other hand, are divided into primary and secondary, referring to the classification proposed in the Conceptual Background. 
In Table 2, the relationship is between the type of stakeholders and the type of rule. In particular, the 15 recommendations are divided between those that have an impact on the sports field and those that instead impact on the economic and social aspects.

The first table shows how two-thirds of the recommendations (10 out of 15) have an impact on the medium-term. In fact, only principles 4 to 8 are short-term. Of these, the first three have to do with primary stakeholders, and the last two with secondary stakeholders. In regards to the ten medium-term points, five refer to primary stakeholders and five to secondary stakeholders.

Table 1. The Relationships between Stakeholders and Time Horizon

\begin{tabular}{|l|c|c|}
\hline Stakeholders & \multicolumn{2}{|c|}{ Principles } \\
\hline Primary & $4,5,8$ & $1,2,3,9,11$ \\
\hline Secondary & 6,7 & $10,12,13,14,15$ \\
\hline Time Horizon & Short & Medium \\
\hline
\end{tabular}

Source: Author's elaboration.

Table 2. The Relationships between Stakeholders and Type of Rules

\begin{tabular}{|l|c|c|}
\hline Stakeholders & \multicolumn{2}{|c|}{ Principles } \\
\hline Primary & 2,8 & $1,3,4,5,9,11$ \\
\hline Secondary & $6,12,13,14,15$ & 7,10 \\
\hline Type of rules & Social Economics & Sport \\
\hline
\end{tabular}

Source: Author's elaboration.

As it is demonstrated, the Table 2 clearly shows a split: the majority of the recommendations concerning the economic aspects impact on the secondary stakeholders, those of the majority concerning the sports aspects impact on the primary stakeholders.

The analysis therefore shows that the $2020+5$ Olympic Agenda includes all the stakeholders of the Olympic movement, and not just the athletes and organizers. The fact that seven recommendations refer to spectators, local institutions, the reference community of the organizing city and the more general production system of the territory, means that the IOC has understood how the only way to guarantee the survival of the Games is to extend the spectrum and to broaden the audience of stakeholders is considered as much as possible.

At the same time, the new rules are not limited to the Games that will come, therefore the summer ones in Tokyo 2021 and the winter ones in Beijing 2022, go to the next editions; those that will give a new connotation to the idea of the Olympic Games - in Paris 2024 in fact, gender equality between men and women in competition will be achieved, with Milan-Cortina 2026 the polycentric organization of the Games will be inaugurated, with more cities involved.

In all of this, the sporting dimension must also be accompanied by the social and economic ones. In fact, the Olympic Games do not only have a sporting relevance, but go further, acquiring a social function and necessarily having to be played in conditions of balance between costs and revenues. 
It is therefore not surprising that in the 2020+ 5 Agenda recommendations that go beyond sporting dynamics are in greater proportions than what had happened with the previous Agenda 2020.

Obviously when discussing this document, we cannot ignore the fact that it follows the 2020 Agenda and must therefore start from the previous results, which is good to summarize.

There were 40 recommendations contained in the Olympic Agenda 2020, developed to safeguard Olympic values and strengthen sport in society. "Change or be changed," was in fact the motto of the process, a fascinating philosophy still today as it was in 2014. Built on three pillars, namely credibility, sustainability and youth, the document is like a mosaic: only when all the pieces will be attacked, the final picture will emerge. Meanwhile, according to what was relaunched by IOC in March 2021, 85\% of the recommendations have been reached and the Agenda has brought about changes and progress in the Olympic movement, laying solid foundations for the future.

Starting with the process of assigning the Games, made to be more cooperative and targeted, the reduction of the average budget for nominations for the winter edition of 2026 came to 5 million dollars, compared to 35 million for 2022. The use of flexible infrastructures has been encouraged, with savings of 5 billion dollars for Tokyo alone. In Paris, $95 \%$ of the offices will be existing or temporary, and in Los Angeles 2028 no new permanent structures are planned.

The biggest reform is the Olympic program. In Paris, gender equality will be achieved for the first time, while before the Agenda, women were $44 \%$ of the competitors. The number of mixed events -where men and women compete together- moved from 8 in 2012, to 18 in Tokyo, up to 22 in Paris. In addition, the additional sports proposed by the IOC and the organizers made the review urban, youthful and feminine. In addition, the Youth Olympic Games have been an innovation laboratory to test new formats, and in 2026 they will be staged in Dakar, the scene of the first Olympic competition in Africa.

The second area of innovation involved athletes. More than 100,000 have signed up for Athlete365, a branch that offers training programs in six languages, while 5,500 have benefited from support in the areas of dual careers and professional transition, so as to have a guaranteed job after retiring from competition.

To ensure a clean sport, the IOC now spends 260 million dollars during the Olympics to fight doping, while as a consequence of the 2020 Agenda, 60 million has been invested in the protection of athletes, creating the International Testing Agency (ITA), encouraging education against rigged competitions and promoting new scientific approaches to anti-doping.

The third area was solidarity. After the 2020 Agenda, the budget allocated to support athletes and national Olympic committees has increased from 311 to 590 million dollars. In recent months alone, during the Coronavirus, the IOC has provided aid of up to 150 million dollars, supporting 1,600 athletes with scholarships, allowing them to continue preparations for the Games postponed to 2021. In addition, the Olympic team of refugees, with projects in Rwanda, Mexico, Turkey, the Democratic Republic of Congo, Kenya, Jordan, Uganda and 
Colombia, so much so that today 200,000 displaced young people have access to safe sports.

In terms of sustainability, the goal is ambitious: to have zero-impact on carbon dioxide emissions by the Games in 2030. On gender equality, on the other hand, today female membership of the IOC is $37.5 \%$, compared to $21 \%$ at the beginning of the 2020 Agenda; women represent $47 \%$ of the members of the commissions, compared to $20 \%$ in 2014 . The IOC has invited all countries to include at least one woman and one man in their teams at the Tokyo Games, giving the opportunity for both a female and a male to carry the flag together during the opening; it will be up to the individual nations to seize, or not, the opportunity.

This reform process has strengthened the confidence of sponsors and business partners, with a positive impact on economic results. The IOC can thus distribute $90 \%$ of its income to support athletes. "Today's success will allow us to lead change for tomorrow," said the number one of the Olympic movement, Thomas Bach, adding: "Thanks to the unity that the 2020 Agenda has created in our environment we can shape the post-Coronavirus, making the world a better place through sport."

Putting together the interests of individual stakeholders, with the points of the 2020 Olympic Agenda, and those of the $2020+5$ Olympic Agenda, it is therefore possible to outline the evolutionary scenario of the new Olympic Games model (Table 3).

Table 3. The Relationships between Stakeholders and Olympic Agendas

\begin{tabular}{|c|c|c|c|}
\hline Stakeholders & Stakes & $\begin{array}{c}\text { After Olympic } \\
\text { Agenda } 2020 \\
\end{array}$ & $\begin{array}{c}\text { After Olympic } \\
\text { Agenda 2020+5 }\end{array}$ \\
\hline Athletes & winning medals & $\begin{array}{c}\text { They are the core of the } \\
\text { Games, gender equality, } \\
\text { battle against doping, } \\
\text { refugees }\end{array}$ & $\begin{array}{l}\text { new rights and } \\
\text { responsibilities, } \\
\text { protection of clean } \\
\text { athletes, development } \\
\text { of virtual sports }\end{array}$ \\
\hline IOC & $\begin{array}{l}\text { managing TV rights and } \\
\text { global sponsorships }\end{array}$ & $\begin{array}{l}\text { Reinforced Games } \\
\text { Image, savings in costs, } \\
\text { major role in the society }\end{array}$ & $\begin{array}{c}\text { New relationships } \\
\text { with athletes, partners } \\
\text { and organizers }\end{array}$ \\
\hline $\begin{array}{l}\text { Organising } \\
\text { Committee }\end{array}$ & $\begin{array}{l}\text { bearing the expenses } \\
\text { and collecting revenues }\end{array}$ & $\begin{array}{l}\text { More flexibility in the } \\
\text { management of the } \\
\text { Venues }\end{array}$ & new legacy plans \\
\hline $\begin{array}{l}\text { International Sport } \\
\text { Federations }\end{array}$ & $\begin{array}{c}\text { obtaining money from } \\
\text { IOC }\end{array}$ & $\begin{array}{l}\text { Protection of clean } \\
\text { athletes, good } \\
\text { governance, increase } \\
\text { solidarity }\end{array}$ & $\begin{array}{l}\text { harmonization of the } \\
\text { sports calendar, new } \\
\text { road to Olympic } \\
\text { Games }\end{array}$ \\
\hline $\begin{array}{l}\text { National Olympic } \\
\text { Committees }\end{array}$ & $\begin{array}{l}\text { supporting preparation } \\
\text { of athletes }\end{array}$ & $\begin{array}{l}\text { Assistance in the phase } \\
\text { of preparation, good } \\
\text { governance, increase } \\
\text { solidarity }\end{array}$ & attracting best athletes \\
\hline Sponsors & increasing their image & $\begin{array}{l}\text { New agreements with } \\
\text { new long deadlines, } \\
\text { trust creates stability }\end{array}$ & $\begin{array}{l}\text { new top partnership } \\
\text { programs }\end{array}$ \\
\hline
\end{tabular}




\begin{tabular}{|c|c|c|c|}
\hline Suppliers & $\begin{array}{l}\text { Obtaining revenues } \\
\text { providing resources }\end{array}$ & $\begin{array}{l}\text { Sustainability, reduced } \\
\text { carbon footprint }\end{array}$ & $\begin{array}{c}\text { Strengthen the role as } \\
\text { an enabler for the UN } \\
\text { Sustainable } \\
\text { Development Goals }\end{array}$ \\
\hline Broadcasters & $\begin{array}{l}\text { widespreading the } \\
\text { Games around the } \\
\text { world }\end{array}$ & $\begin{array}{c}\text { Launch of Olympic } \\
\text { Channel }\end{array}$ & $\begin{array}{l}\text { Innovate revenue } \\
\text { generation model }\end{array}$ \\
\hline Other Media & $\begin{array}{c}\text { promoting the } \\
\text { knowledge of the } \\
\text { Games }\end{array}$ & $\begin{array}{l}\text { New contents, New } \\
\text { presence in the Social } \\
\text { Media }\end{array}$ & $\begin{array}{c}\text { New engagement with } \\
\text { athletes }\end{array}$ \\
\hline Workforce & creating the event & $\begin{array}{l}\text { New more massive and } \\
\text { inclusive involvement }\end{array}$ & Good governance \\
\hline Volunteers & creating the event & $\begin{array}{l}\text { New more massive and } \\
\text { inclusive involvement }\end{array}$ & Good governance \\
\hline Spectators & $\begin{array}{l}\text { playing an active role } \\
\text { during competitions }\end{array}$ & $\begin{array}{l}\text { New ways to attend to } \\
\text { the events }\end{array}$ & digital engagement \\
\hline $\begin{array}{l}\text { Organizers of next } \\
\text { Olympic Games }\end{array}$ & $\begin{array}{l}\text { learning from the past } \\
\text { to improve the future }\end{array}$ & $\begin{array}{l}\text { Shortened the time of } \\
\text { their commitment and } \\
\text { savings in costs }\end{array}$ & new legacy plans \\
\hline
\end{tabular}

Source: Author's elaboration.

These will be the Games of the future, which we will have to get used to, since the "Paris 2024" edition, the first of the new, more inclusive and open Olympiad model.

\section{Conclusion}

Paris is worth a mass, that of gender equality between men and women in the Olympic field. In 2024, in the shadow of the Eiffel Tower, the five-circle athletes will be equally divided between males and females: 5250 in blue, as many in pink. It is suggestive that this happens precisely in the French capital, already the scene in 1900 of the first appearance, albeit as a demonstration, of women in the Olympic context, and in 1922 of the inaugural edition of the provocative women's Olympic Games. The finish line was in the air, but to be reached it took a last mile driven at the spur of the IOC, which heavily worked on the new Games program. There are those who have gained and those who have lost within the individual national federations, but the moral winner of the reform is precisely the IOC, which in one fell swoop has put men and women on the same level (in Tokyo instead the boys will be the $51.2 \%$, women $48.8 \%$ ), increasing mixed events (from 18 to 22), reaching gender parity in 28 out of 32 sports (in gymnastics and swimming, thanks to rhythmic and synchronized in women, football and wrestling, thanks to the greater number of teams and the Greco-Roman, men), but reducing both the total number of athletes (from 11,092 to 10,500) and the events that will award medals )from 339 to 329 ).

The four sports admitted as add-ons following the organizers' proposal are rejoicing: break dance (at the absolute debut at the Games), surfing (which will be held in Tahiti, in the Pacific Ocean), skateboarding and climbing. The last three will already be present in Tokyo next year as well, along with karate and baseball/ 
softball, which will leave the company after 2021 (both have proven unpopular in France).

Within the classic sports, those that saw their proposals for change approved were canoeing, sailing and shooting. The sport of paddling will introduce extreme slalom competitions, where you compete against the opponent and not against the clock, at the expense of two flat water speed tests. In sailing, on stage in Marseille, the revolution is total. The traditional classes will remain three (the two Lasers and the 470 mixed with a man and a woman), while the acrobatic classes will be six; the two Windfoils, instead of Windsurfing, with the boards that, instead of gliding, will fly over the water, the Nacra Foil, the two 49ers and the Kiteboarding, that is the board with the kite with a man and a woman who will compete in the relay. The question mark remains about a new mixed event; it should be an offshore test that could represent the first step towards ocean sailing at the Games. Finally, in volley shooting, the mixed test will no longer be in the pit, but in skeet.

All other proposals were rejected, as they did not respect the three constraints placed by the IOC on the Federations: any insertions should not have involved the construction of new facilities, an increase in the number of athletes and an increase in the number of medals. Thus, gymnastics had to give up parkour, handball to the beach version, rowing to coastal competitions, and athletics to cross-country running, while swimming had previously withdrawn the proposal for dives from great heights and 50 meters breaststroke, backstroke and butterfly. The Queen of Olympic sports holds 48 events, but greets the men's $50 \mathrm{~km}$ walk, replaced by a new mixed heel and toe competition. Worse has gone to boxing and weightlifting. On the square, a female category will replace a male one, while the weights will discount the problems that have emerged in terms of doping and governance with the cancellation of four categories and the reduction of athletes from 196 to 120 .

So far the news from Lausanne, and even in the Ville Lumiere, there is something brewing in the pot. In fact, a revolution in the geography of five-circle places is be announced. To keep costs down, four facilities (the rugby stadium, the volleyball hall, the St. Denis swimming pool and the Zenith for weight lifting) will not be built, so there will be a reshuffling of the disciplines in the remaining poles. The Bercy building will therefore host artistic gymnastics in the first week and basketball in the second, the rhythmic will emigrate to Porte de la Chapelle, swimming will end up in Defense, handball even in Lille. Greater dispersion, but lower costs. It is the wallet that dictates the choices.

In summary, it is possible to note how the 2020 Agenda has made possible a greater involvement of individual stakeholders around the Olympic Games. Individual actors are now more included in the idea of Games, which has become over time more open to the attention of individual subjects.

This paper focused on the continuation of the 2020 Agenda, i.e., the $2020+5$ Olympic Agenda, the recommendations of which were approved in March 2021.

Compared to the previous literature, the paper did not intend to present a concrete case of application, but simply an investigation of the principles in order to better outline the new model of the Olympic Games that we will have to face in the coming years. 
The current limitation of the paper is that the analysis was based only on documents produced by the IOC. At the same time, the future development can be to extend the analysis by also involving the documents produced by the other stakeholders of the Games, such as the International Federations, the Organizing Committees and the National Olympic Committees.

\section{References}

Clarkson MBE (1995) A stakeholder framework for analysing and evaluating corporate social performance. Academy of Management Review 20(1): 92-117.

Freeman RE (1984) Strategic management: a stakeholder approach. Boston: Pitman.

Freeman RE (1994) The politics of stakeholder theory: some future directions. Business Ethics Quarterly 4(4): 409-421.

Freeman RE, Reed DL (1983) Stockholders and stakeholders: a new perspective on corporate governance. California Management Review 25(3): 88-106.

International Olympic Committee - IOC (2014) Olympic Agenda 2020: context and background. Montecarlo: IOC.

International Olympic Committee - IOC (2015) Olympic Agenda 2020: 20+20 recommendations. Lausanne: IOC.

International Olympic Committee - IOC (2020) Olympic Agenda 2020 drives progress and change. Retrieved from: https://www.olympic.org/news/olympic-agenda-2020drives-progress-and-change. [Accessed 21 December 2021]

International Olympic Committee - IOC (2021) IOC executive board proposes Olympic Agenda 2020+5 as the strategic roadmap to 2025. Retrieved from: https://www. olym \#pic.org/olympic-agenda-2020-plus-5. [Accessed 1 April 2021]

MacAloon JJ (2016) Agenda 2020 and the Olympic movement. Sport in Society Cultures, Commerce, Media, Politics 19(6): 767-785.

Mataruna Dos Santos LJ, Zardini Filho CE, Cazorla A (2019) Youth Olympic Games: using marketing tools to analyse the reality of GCC countries beyond Agenda 2020. Journal of Human Sport and Exercise 14(3proc): S391-S411.

Schnitzer M, Haizinger L (2019) Does the Olympic Agenda 2020 have the power to create a new Olympic heritage? An analysis for the 2026 Winter Olympic Games bid. Sustainability 11(2): 442.

Thorpe H, Wheaton B (2019) The Olympic Games, Agenda 2020 and action sports: the promise, politics and performance of organisational change. International Journal of Sport Policy and Politics 11(3): 465-483. 
